\title{
Prescription omega-3 fatty acid products: considerations for patients with diabetes mellitus
}

This article was published in the following Dove Press journal:

Diabetes, Metabolic Syndrome and Obesity:Targets and Therapy

19 April 2016

Number of times this article has been viewed

\author{
Nadeem Tajuddin' \\ Ali Shaikh² \\ Amir Hassan ${ }^{2}$ \\ 'Department of Internal Medicine, \\ Baylor College of Medicine, Houston, \\ TX, USA; ${ }^{2}$ Clinic of Endocrinology, \\ Houston, TX, USA
}

\begin{abstract}
Type 2 diabetes mellitus (T2DM) and metabolic syndrome contribute to hypertriglyceridemia, which may increase residual risk of cardiovascular disease in patients with elevated triglyceride (TG) levels despite optimal low-density lipoprotein cholesterol (LDL-C) levels with statin therapy. Prescription products containing the long-chain omega-3 fatty acids (OM3FAs) eicosapentaenoic acid (EPA) and docosahexaenoic acid (DHA) are an effective strategy for reducing TG levels. This article provides an overview of prescription OM3FAs, including relevant clinical data in patients with T2DM and/or metabolic syndrome. Prescription OM3FAs contain either combinations of DHA and EPA (omega-3-acid ethyl esters, omega-3-carboxylic acids, omega-3-acid ethyl esters A) or EPA alone (icosapent ethyl). These products are well tolerated and can be used safely with statins. Randomized controlled trials have demonstrated that all prescription OM3FAs produce statistically significant reductions in TG levels compared with placebo; however, differential effects on LDL-C levels have been reported. Products containing DHA may increase LDL-C levels, whereas the EPA-only product did not increase LDL-C levels compared with placebo. Because increases in LDL-C levels may be unwanted in patients with T2DM and/or dyslipidemia, the EPA-only product should not be replaced with products containing DHA. Available data on the effects of OM3FAs in patients with diabetes and/or metabolic syndrome support that these products can be used safely in patients with T2DM and have beneficial effects on atherogenic parameters; in particular, the EPA-only prescription product significantly reduced TG, non-high-density lipoprotein cholesterol, Apo B, remnant lipoprotein cholesterol, and high-sensitivity CRP levels without increasing LDL-C levels compared with placebo. Ongoing studies of the effects of prescription OM3FAs on cardiovascular outcomes will help determine whether these products will emerge as effective add-on options to statin therapy for reduction of residual cardiovascular disease risk.
\end{abstract}

Keywords: docosahexaenoic acid, dyslipidemia, eicosapentaenoic acid, hypertriglyceridemia, icosapent ethyl, omega-3 fatty acids, triglycerides

\section{Introduction}

Metabolic syndrome is prevalent worldwide and is associated with an increased risk of type 2 diabetes mellitus (T2DM). ${ }^{1}$ Patients with T2DM and/or metabolic syndrome have a substantially elevated risk of cardiovascular disease (CVD). ${ }^{2,3}$ In addition, both T2DM and metabolic syndrome are known contributors to hypertriglyceridemia, which is increasingly being recognized as a risk factor for CVD. ${ }^{4,5}$

Even with optimized statin therapy (ie, achieving target low-density lipoprotein cholesterol [LDL-C] levels), patients may continue to have elevated levels of other atherogenic parameters such as Apo B and non-high-density lipoprotein cholesterol
Correspondence: Nadeem Tajuddin Department of Internal Medicine, Baylor College of Medicine, One Baylor Plaza, Houston, TX 77030, USA

$\mathrm{Tel}+\mathrm{I} 2819224000$

Fax +l 28I 9224242

Email nadeem.tajuddin@bcm.edu 
(non-HDL-C), which, along with elevated triglyceride (TG) levels, may contribute to an increased residual risk for CVD. $^{5-7}$ Addressing this residual risk represents a major health care challenge. ${ }^{8}$

Prescription products containing the long-chain omega-3 fatty acids (OM3FAs) eicosapentaenoic acid (EPA) and docosahexaenoic acid (DHA) are an effective strategy for reducing TG levels in patients with hypertriglyceridemia. ${ }^{9-15}$ This review provides a comparative overview of approved prescription OM3FAs and discusses clinical data in patients with T2DM and/or metabolic syndrome.

\section{Overview of endocrine/diabetes recommendations on use of prescription OM3FAs}

Several leading endocrine and/or diabetes organizations recognize the important role of prescription OM3FAs in the treatment of patients with moderate to severely elevated TG levels, as reflected in their treatment recommendations (Table 1). ${ }^{4,16-19}$ The American Association of Clinical Endocrinologists/American College of Endocrinology Clinical Guidelines for Developing a Diabetes Mellitus Comprehensive Care Plan ${ }^{16,17}$ contain specific recommendations regarding the use of prescription OM3FAs in patients with diabetes, including use in the setting of residual risk. Highdose prescription OM3FAs are recognized as an effective option for lowering TG levels in patients with TG levels $\geq 500$ $\mathrm{mg} / \mathrm{dL}^{16}$ and high-dose OM3FAs have been recommended for achieving target non-HDL-C levels in patients with TG levels $\geq 200 \mathrm{mg} / \mathrm{dL}$ and HDL-C levels $<35 \mathrm{mg} / \mathrm{dL}$ or in patients with persistently elevated fasting TG levels $>200 \mathrm{mg} / \mathrm{dL}$ despite maximally tolerated LDL-C-lowering therapies. ${ }^{17}$ In addition, the International Diabetes Federation Global Guideline for Type 2 Diabetes recommends that patients with T2DM unable to achieve lipid-lowering targets with or are intolerant of conventional medications (statins or fenofibrate) should be considered as candidates for other medications for dyslipidemia, including high-dose OM3FAs. ${ }^{19}$ The 2012 Endocrine Society clinical practice guideline on evaluation and treatment of hypertriglyceridemia, though not specific to patients with T2DM, recommends that drug therapies such as fibrates, niacin, or OM3FAs (alone or in combination with statins) be considered for treatment of moderate to severe TG levels. ${ }^{4}$ The American Diabetes Association (ADA) 2016 Standards of Medical Care in Diabetes recommends that statin therapy be considered for all patients with diabetes (with high-intensity statins recommended for those with overt CVD or with greater CVD risk), and although the consumption of foods containing long-chain OM3FAs is recommended, there is no evidence to support the use of OM3FA supplements for the prevention of cardiovascular risk. ${ }^{18}$

\section{Prescription OM3FA products}

A summary of the OM3FAs approved by the US Food and Drug Administration (FDA) is provided in Table 2. ${ }^{14,20-24}$ All prescription OM3FAs are indicated as an adjunct to diet to reduce TG levels in adult patients with severe $(\geq 500 \mathrm{mg} / \mathrm{dL})$ hypertriglyceridemia. ${ }^{21-24}$ Only one prescription product, icosapent ethyl (Vascepa ${ }^{\circledR}$; Amarin Pharma Inc., Bedminster, NJ, USA), contains only high-purity EPA. The other

Table I Overview of endocrine/diabetes recommendations on use of prescription OM3FAs

\begin{tabular}{|c|c|c|c|}
\hline $\begin{array}{l}\text { Association/ } \\
\text { Society }\end{array}$ & Year & $\begin{array}{l}\text { Target } \\
\text { population }\end{array}$ & Recommendation(s) \\
\hline $\mathrm{AACE} / \mathrm{ACE} \mathrm{E}^{16,17}$ & 2015,2016 & Diabetes & $\begin{array}{l}\text { Prescription OM3FAs, fibrates, or niacin may also be used to reduce TG levels that are }>500 \mathrm{mg} / \mathrm{dL} \text {. } \\
\text { In patients who have LDL-C levels at goal but TG concentrations } \geq 200 \mathrm{mg} / \mathrm{dL} \text { and low HDL-C } \\
\text { ( }<35 \mathrm{mg} / \mathrm{dL} \text { ), treatment protocols that include fibrates, niacin, or high-dose OM3FAs may be used to } \\
\text { achieve the non-HDL-C goal. } \\
\text { In the setting of persistently elevated fasting TG levels ( }>200 \mathrm{mg} / \mathrm{dL} \text { ) against the background of } \\
\text { maximally tolerated LDL-C-lowering therapies, TG-reducing therapies such as fibrates, high-dose } \\
\text { OM3FAs, or niacin may be utilized to further reduce non-HDL-C. }\end{array}$ \\
\hline $\mathrm{ADA}^{18}$ & 2016 & Diabetes & $\begin{array}{l}\text { No mention of recommendations regarding prescription OM3FAs. } \\
\text { Evidence does not support recommending OM3FA supplements for people with diabetes for the } \\
\text { prevention or treatment of cardiovascular events. }^{\text {a }}\end{array}$ \\
\hline $\mathrm{IDF}^{19}$ & 2012 & Diabetes & $\begin{array}{l}\text { Consider other medications for dyslipidemia (bile acid binding resins, ezetimibe, sustained-release } \\
\text { nicotinic acid, concentrated OM3FAs) in patients failing to reach lipid-lowering targets or intolerant of } \\
\text { conventional medications. }\end{array}$ \\
\hline $\begin{array}{l}\text { Endocrine } \\
\text { Society }\end{array}$ & 2012 & General & $\begin{array}{l}\text { Suggest that three drug classes (fibrates, niacin, OM3FAs) alone or in combination with statins be } \\
\text { considered as treatment options in patients with TG levels } \geq 200-1,999 \mathrm{mg} / \mathrm{dL} \text {. }\end{array}$ \\
\hline
\end{tabular}

Note: ${ }^{\mathrm{a}}$ The ADA guidelines do not discuss the role of prescription OM3FAs in patients with diabetes.

Abbreviations: AACE, American Association of Clinical Endocrinologists; ACE, American College of Endocrinology; ADA, American Diabetes Association; HDL-C, highdensity lipoprotein cholesterol; IDF, International Diabetes Federation; LDL-C, low-density lipoprotein cholesterol; OM3FAs, omega-3 fatty acids; TG, triglyceride. 
Table 2 Overview of FDA-approved prescription OM3FAs

\begin{tabular}{|c|c|c|c|c|}
\hline \multicolumn{5}{|c|}{ Indication (all): adjunct to diet to reduce TG levels in adult patients with severe ( $\geq 500 \mathrm{mg} / \mathrm{dL}$ ) hypertriglyceridemia } \\
\hline $\begin{array}{l}\text { Prescription } \\
\text { product }\end{array}$ & $\begin{array}{l}\text { Omega-3-acid ethyl } \\
\text { esters }^{20,21, a}\end{array}$ & Icosapent ethy|22 & $\begin{array}{l}\text { Omega-3-carboxylic } \\
\text { acids }^{14,23, b}\end{array}$ & $\begin{array}{l}\text { Omega-3-acid ethyl } \\
\text { esters } A^{24, b}\end{array}$ \\
\hline $\begin{array}{l}\text { OM3FA content } \\
\text { (in each capsule }^{c} \text { ) }\end{array}$ & $\begin{array}{l}\geq 0.9 \mathrm{~g} \text { OM3FA ethyl } \\
\text { esters from fish oils } \\
\text { EPA } \sim 0.465 \mathrm{~g} \\
\text { DHA } \sim 0.375 \mathrm{~g}\end{array}$ & $\begin{array}{l}\text { I g icosapent ethyl } \\
\text { EPA I g }\end{array}$ & $\begin{array}{l}\geq 0.85 \mathrm{~g} \mathrm{OM} 3 \text { carboxylic } \\
\text { acids from fish oils } \\
\text { EPA } 0.55 \mathrm{~g} \\
\text { DHA } 0.2 \mathrm{~g}\end{array}$ & $\begin{array}{l}\geq 0.9 \mathrm{~g} \text { OM } 3 F A \text { ethyl } \\
\text { esters from fish oils } \\
\text { EPA } \sim 0.465 \mathrm{~g} \\
\text { DHA } \sim 0.375 \mathrm{~g}\end{array}$ \\
\hline Total daily dose & $4 \mathrm{~g}$ & $4 \mathrm{~g}$ & 2 or $4 \mathrm{~g}$ & $4 \mathrm{~g}$ \\
\hline \multirow[t]{2}{*}{ Dosing schedule } & $\begin{array}{l}4 \text { capsules QD } \\
\text { or } \\
2 \text { capsules BID }\end{array}$ & 2 capsules BID & $\begin{array}{l}4 \text { capsules QD } \\
\text { or } \\
2 \text { capsules QD }\end{array}$ & $\begin{array}{l}4 \text { capsules QD } \\
\text { or } \\
2 \text { capsules BID }\end{array}$ \\
\hline & $\begin{array}{l}\text { Can be taken without } \\
\text { regard to meals }\end{array}$ & $\begin{array}{l}\text { Should be taken } \\
\text { with meals }\end{array}$ & $\begin{array}{l}\text { Can be taken without } \\
\text { regard to meals }\end{array}$ & $\begin{array}{l}\text { Should be taken with } \\
\text { meals }\end{array}$ \\
\hline AE profile ${ }^{d}$ & $\begin{array}{l}\text { Eructation, dyspepsia, } \\
\text { taste perversion }\end{array}$ & Arthralgia & $\begin{array}{l}\text { Diarrhea, nausea, } \\
\text { abdominal pain or } \\
\text { discomfort, eructation }\end{array}$ & $\begin{array}{l}\text { Eructation, dyspepsia, } \\
\text { taste perversion }\end{array}$ \\
\hline
\end{tabular}

Notes: a Generic prescription products are available. ${ }^{b}$ Approved but not commercially available at the time of writing this paper. ${ }^{\mathrm{C} O m e g a-3-a c i d ~ e t h y l ~ e s t e r s, ~ i c o s a p e n t ~ e t h y l, ~}$ and omega-3-carboxylic acids have I g capsules; the omega-3-acid ethyl esters A capsule is $1.2 \mathrm{~g}$. Most common AEs as noted in product labeling: omega-3-acid ethyl esters and omega-3-acid ethyl esters A have identical safety data and AEs listed are those with an incidence $\geq 3 \%$ and greater than placebo; icosapent ethyl AEs are those with incidence $>2 \%$ and greater than placebo; omega-3-carboxylic acids AEs are those for patients receiving $4 \mathrm{~g}$ with an incidence $\geq 3 \%$ and greater than placebo.

Abbreviations: AE, adverse event; BID, twice daily; DHA, docosahexaenoic acid; EPA, eicosapentaenoic acid; FDA, United States Food and Drug Administration; OM3, omega-3; OM3FA, omega-3 fatty acid; QD, once daily; TG, triglyceride.

prescription products contain both DHA and EPA and include omega-3-acid ethyl esters (Lovaza ${ }^{\circledR}$; GlaxoSmithKline, plc, London, UK), generic omega-3-acid ethyl esters, omega-3carboxylic acids (Epanova ${ }^{\circledR}$; AstraZeneca plc, London, UK), and omega-3-acid ethyl esters A (Omtryg ${ }^{\mathrm{TM}}$; Trygg Pharma, Inc., Arlington, VA, USA).

\section{Safety/tolerability}

As a therapeutic class, prescription OM3FAs have a wellestablished safety profile and are generally well tolerated. ${ }^{21-24}$ In the clinical studies that supported their respective FDA approvals, gastrointestinal adverse events were seen more frequently with products containing DHA (omega-3-acid ethyl esters, omega-3-acid ethyl esters A, and omega-3carboxylic acids) compared with the EPA-only product (icosapent ethyl) (Table 2).12,13,21-24 Two recent systematic reviews and a meta-analysis seem to support that OM3FAs can be used safely in patients with T2DM, with no significant changes in glycated hemoglobin (HbAlc), fasting plasma glucose, fasting insulin, insulin sensitivity, body weight, or impairment of glucose metabolism. ${ }^{25-27}$ A sub-analysis of patients with diabetes $(n=513)$ from the ANCHOR study, which assessed the efficacy and safety of icosapent ethyl in statin-treated patients at high cardiovascular risk with wellcontrolled LDL-C and residually high TG levels ( $\geq 200$ and $<500 \mathrm{mg} / \mathrm{dl}$ ), supports these conclusions. ${ }^{13,28}$ Compared with placebo, no significant increases in fasting plasma glucose, HbA1c, insulin, or homeostasis model assessment-estimated insulin resistance were found in patients with diabetes treated with icosapent ethyl $4 \mathrm{~g} /$ day over a 12 -week study period. $^{28}$

The favorable safety and tolerability profile of prescription OM3FAs as a class is an important consideration when selecting treatment, especially given that use of other TGlowering drug classes (ie, fibrates, niacin) may be limited by side effects. Both fibrates and niacin have been associated with an increased risk of myopathy and rhabdomyolysis, especially when used in combination with statins. ${ }^{29-33}$ In contrast, prescription OM3FAs have not been associated with increased risk of myopathy when used alone or in combination with statins. ${ }^{21-24}$ Tolerability is a common issue with niacin due to flushing episodes, which have been reported to occur in $\geq 75 \%$ of patients. ${ }^{33,34}$ A particular concern for patients who have or are at risk for diabetes is that niacin can increase serum glucose levels; thus, it is recommended that glucose levels be monitored closely in such patients. ${ }^{33}$ Finally, in some patients with high and very high TG levels, fibrates have been associated with significant LDL-C increases or attenuation of LDL-C reduction effects of statins..$^{30,35-38}$ Of note, in April 2015, the labeling for both fenofibric acid (Trilipix, AbbVie, Inc., North Chicago, IL, USA) and niacin extended release (Niaspan, AbbVie, Inc.) was revised to remove any wording related to indication/ dosing in combination with statins due to a lack of clinical evidence for cardiovascular benefit as adjuncts to statin therapy. ${ }^{32,33}$ 


\section{Drug interactions}

No drug-drug interaction concerns have been raised with prescription OM3FAs. An investigation of co-administration of icosapent ethyl with the oral antidiabetes agent rosiglitazone did not identify a drug-drug interaction for this combination. ${ }^{22,39}$ In other investigations, no drug-drug interactions were identified between icosapent ethyl and atorvastatin, ${ }^{40}$ warfarin, ${ }^{41}$ or omeprazole ${ }^{42}$ or between omega-3-acid ethyl esters and simvastatin, ${ }^{43}$ rosuvastatin, ${ }^{44}$ or atorvastatin. ${ }^{45}$ However, patients receiving treatment with prescription OM3FAs in addition to other drugs affecting coagulation should be monitored periodically. ${ }^{21-24}$ This is because prolongation of bleeding time has been reported in some published studies of OM3FAs, although bleeding time was still within normal limits and did not cause clinically significant bleeding episodes. ${ }^{21-24}$ Notably, evidence-based reviews have supported a lack of effect of OM3FAs on clinically significant bleeding, even in patients taking medications that affect coagulation. $^{46-48}$

\section{Distinctions between prescription OM3FAs and fish oil dietary supplements}

Fish oil dietary supplements are widely available and commonly used by consumers; however, there are critical distinctions between these dietary supplements and the FDA-approved OM3FA drugs that can be obtained only by prescription. Notably, although fish oil dietary supplements can be purchased without a prescription, they are not overthe-counter (OTC) drugs; in fact, there are no approved OTC OM3FA products in the USA. In stark contrast to prescription and OTC drugs/medications, which are subject to rigorous regulatory standards, OM3FA dietary supplements may contain inconsistent EPA and DHA quantities and be of variable quality. ${ }^{49-55} \mathrm{~A}$ recent study evaluating OMFA3 content and oxidative markers in fish oil dietary supplements in New Zealand found that $83 \%$ of supplements exceeded the recommended peroxide level..$^{53}$ Importantly, dietary supplements are not required to demonstrate the safety or efficacy of their ingredients prior to marketing and are considered safe until proven otherwise..$^{51,56-58}$ In contrast, prescription OM3FA products are highly purified, subject to quality control regulations, and required to demonstrate both safety and efficacy in clinical studies to achieve approval by the FDA. Another distinction is that fish oil dietary supplements may require a high pill burden to achieve prescription-strength doses $^{59}$ while the pill count is a maximum of four capsules/ day for the prescription products. It is also worth noting that OM3FA dietary supplementation at doses of $1 \mathrm{~g} /$ day did not reduce the rate of cardiovascular events in high-risk patients. ${ }^{60}$ Indeed, both the International Atherosclerosis Society and the ADA have moved away from recommending the use of OM3FA dietary supplements for the prevention or treatment of cardiovascular events. ${ }^{61,62}$ Given these concerns related to efficacy, quality, and safety of dietary supplements, these products should not be considered appropriate substitutes for prescription OM3FA products in patients who require TG-lowering treatment.

\section{Key prescription OM3FA clinical studies}

A summary of key clinical studies of prescription OM3FAs in patients with very high TG levels (with or without statin therapy) or high TG levels (with statin therapy), is provided in Table 3.

\section{TG-lowering effects}

In randomized placebo-controlled clinical studies, all prescription OM3FAs have demonstrated statistically significant reductions in TG levels compared with placebo (Table 3). ${ }^{9-15,21,23,24}$ TG reductions were also statistically significant in patients treated with prescription OM3FAs in combination with statins. ${ }^{11,13,15}$ It has been consistently shown that higher baseline TG levels are associated with a greater degree of TG reduction. ${ }^{12,63,64}$ This relationship between baseline TG level and observed TG reduction helps explain the range of TG lowering observed among the studies of prescription OM3FAs in patients with very high TG levels (Table 3). Greater reductions in TG levels reported in the omega-3-acid ethyl esters prescribing information may be attributable to baseline TG levels that were more than $100 \mathrm{mg} / \mathrm{dL}$ higher in those studies in comparison with baseline TG levels in studies of other prescription OM3FAs (Table 3). In a head-to-head study of omega-3-acid ethyl esters and omega-3-acid ethyl esters A (Table 4) ${ }^{65}$ the baseline TG level was $655 \mathrm{mg} / \mathrm{dL}$ in the omega-3-acid ethyl esters group. This was lower than the baseline TG level in the pivotal omega-3-acid ethyl esters data shown in Table 3, and was more in line with the baseline TG levels in the studies of the other OM3FA products. Accordingly, the TG reductions observed for the omega-3-acid ethyl esters group in the head-to-head study were similar to those reported for the other OM3FAs (Tables 3 and 4).

\section{Effects on LDL-C and other parameters}

Differential effects on LDL-C levels have been demonstrated in clinical trials of prescription OM3FAs when compared with placebo: treatment with products containing both EPA and 
Table 3 Summary of randomized placebo-controlled clinical studies of prescription OM3FAs

\begin{tabular}{|c|c|c|c|c|c|c|c|c|c|}
\hline \multirow[t]{2}{*}{$\begin{array}{l}\text { Prescription } \\
\text { OM3FA } \\
\text { product }\end{array}$} & \multirow[t]{2}{*}{ Study } & \multirow[t]{2}{*}{ TG level $^{\mathbf{a}}$} & \multirow[t]{2}{*}{$\begin{array}{l}\text { Concomitant } \\
\text { statin use }\end{array}$} & \multirow[t]{2}{*}{$\begin{array}{l}\text { Proportion } \\
\text { of patients } \\
\text { with diabetes }\end{array}$} & \multirow[t]{2}{*}{$\mathbf{N}$} & \multicolumn{4}{|c|}{$\begin{array}{l}\text { Effects of } 4 \text { g/day prescription OM3FA on } \\
\text { atherogenic parameters } \\
\text { (difference vs placebo) }\end{array}$} \\
\hline & & & & & & Parameter & $\begin{array}{l}\text { Baseline } \\
\text { (mg/dL) }\end{array}$ & $\begin{array}{l}\text { Change } \\
\text { (\%) }\end{array}$ & $P$-value \\
\hline \multirow{10}{*}{$\begin{array}{l}\text { Omega-3-acid } \\
\text { ethyl esters }\end{array}$} & Pooled pivotal studies ${ }^{9,10,21}$ & Very high & NR & NR & 84 & $\mathrm{TG}^{\mathrm{b}}$ & 816 & $-51.6^{c}$ & $\leq 0.05^{d}$ \\
\hline & & & & & & LDL-C $^{b}$ & 89 & +49.3 & $\leq 0.05^{d}$ \\
\hline & & & & & & Apo B ${ }^{b}$ & $N R$ & $N R$ & NR \\
\hline & & & & & & Non-HDL-C ${ }^{b}$ & 271 & -10.2 & NR \\
\hline & & & & & & hsCRPb & $N R$ & $N R$ & NR \\
\hline & $\operatorname{COMBOS}^{11,20}$ & High & All patients & NR & 254 & TG & 268 & $-23.2^{\mathrm{e}}$ & $<0.0001$ \\
\hline & & & & & & LDL-C & 91 & $+3.5^{\mathrm{e}}$ & 0.05 \\
\hline & & & & & & Apo B & 86 & $-2.3^{\mathrm{e}}$ & $<0.05$ \\
\hline & & & & & & Non-HDL-C & 137 & $-6.8^{e}$ & $<0.0001$ \\
\hline & & & & & & hsCRP & $N R$ & $N R$ & NR \\
\hline \multirow[t]{10}{*}{ Icosapent ethyl } & MARINE ${ }^{12,22,69}$ & Very high & $25 \%$ & $28 \%$ & 229 & TG & 680 & -33.1 & $<0.0001$ \\
\hline & & & & & & LDL-C & 91 & -2.3 & $N S^{d}$ \\
\hline & & & & & & Apo B & 121 & -8.5 & $<0.01$ \\
\hline & & & & & & Non-HDL-C & 225 & -17.7 & $<0.000 \mathrm{I}^{\mathrm{d}}$ \\
\hline & & & & & & hsCRP & 0.22 & -36.0 & 0.0005 \\
\hline & $\mathrm{ANCHOR}^{13}$ & High & All patients & $73 \%$ & 702 & TG & 265 & -21.5 & $<0.0001$ \\
\hline & & & & & & LDL-C & 82 & -6.2 & $<0.01$ \\
\hline & & & & & & Apo B & 93 & -9.3 & $<0.0001$ \\
\hline & & & & & & Non-HDL-C & 128 & -13.6 & $<0.0001$ \\
\hline & & & & & & hsCRP & 0.22 & -22.0 & 0.0005 \\
\hline \multirow{6}{*}{$\begin{array}{l}\text { Omega-3- } \\
\text { carboxylic } \\
\text { acids }\end{array}$} & EVOLVE $^{14,23}$ & Very high & $34 \%-35 \%$ f,g & $30 \%-45 \%^{f}$ & 399 & TG & 655 & -21 & $<0.00 \mathrm{I}$ \\
\hline & & & & & & LDL-C & 90 & +15 & $<0.00 \mathrm{I}^{\mathrm{d}}$ \\
\hline & & & & & & Apo B & 118 & +2 & $N S^{d}$ \\
\hline & & & & & & Non-HDL-C & 225 & -10 & $<0.01$ \\
\hline & & & & & & hsCRP & $0.23^{\mathrm{h}}$ & -0.3 & NS \\
\hline & ESPRIT ${ }^{15}$ & High & All patients & $69 \%-74 \%^{f}$ & 647 & \multicolumn{4}{|c|}{$\begin{array}{l}\% \text { differences vs placebo not reported; within- } \\
\text { group least squares geometric mean changes } \\
\text { were reported for TG }(-21 \%) \text {, total cholesterol } \\
(-3.8 \%) \text {, non-HDL-C (-6.9\%), Apo B (-2.I\%) (all } \\
\text { statistically significant vs placebo), and LDL-C } \\
(+1.3 \% \text {; NS) }\end{array}$} \\
\hline Omega-3-acid & Available only in prescribing & Very high & $21 \%$ & NR & 254 & TG & 702 & -12.2 & $<0.05$ \\
\hline \multirow[t]{4}{*}{ ethyl esters $A$} & information; ${ }^{24}$ not published & & & & & LDL-C & 237 & +24.7 & $<0.01$ \\
\hline & elsewhere; no data available & & & & & Apo B & $N R$ & NR & NR \\
\hline & in patients with high TG & & & & & Non-HDL-C & 237 & -8.5 & NR \\
\hline & & & & & & hsCRP & $N R$ & $N R$ & NR \\
\hline
\end{tabular}

Notes: avery high TG level defined as $\geq 500$ and $\leq 2,000 \mathrm{mg} / \mathrm{dL}$ in the icosapent ethyl and omega-3-acid ethyl esters studies, $\geq 500$ and $<2,000 \mathrm{mg} / \mathrm{dL}$ for omega-3-carboxylic acids study, and $\geq 500$ and $\leq 1,500 \mathrm{mg} / \mathrm{dL}$ for omega- 3 -acid ethyl esters $\mathrm{A}$; high TG level defined as $\geq 200$ and $<500 \mathrm{mg} / \mathrm{dL}$ in all studies. ${ }^{\text {bData }}$ pooled from Harris et al and Pownall et al and reported in prescribing information. $\left.{ }^{9.10,21 ~ c H i g h ~ b a s e l i n e ~ T G ~ l e v e l s ~ i n ~ t h e s e ~ p o o l e d ~ s t u d i e s ~(~} 816 \mathrm{mg} / \mathrm{dL}\right)$ contributed to greater TG reduction relative to that observed in other studies of prescription OM3FAs. ${ }^{\mathrm{P}} \mathrm{P}$-value not reported in product labeling but available in corresponding publication(s). ${ }^{\mathrm{e}}$ ercent changes vs placebo not reported in the COMBOS publication" but reported in 2013 version of the omega-3-acid ethyl esters product prescribing information. ${ }^{20}$ Range across all treatment arms. sPercentage reflects use of statins, cholesterol absorption inhibitors, or a combination of these products. hPercentage differences vs placebo not reported; values represent absolute least square geometric mean change from baseline.

Abbreviations: Apo B, apolipoprotein B; hsCRP, high-sensitivity C-reactive protein; LDL-C, low-density lipoprotein cholesterol; OM3FA, omega-3 fatty acid; non-HDL-C, non-high-density lipoprotein cholesterol; NR, not reported; NS, not statistically significant $(P \geq 0.05)$; TG, triglyceride.

DHA (omega-3-acid ethyl esters, omega-3-carboxylic acids, omega-3-acid ethyl esters A) resulted in increased median LDL-C levels, whereas treatment with EPA alone (icosapent ethyl) resulted in a minimal reduction or neutral effect on LDL-C levels (Table 3). ${ }^{9,10,12-14,21-24}$ The LDL-C increase may be attributed to DHA: in a pooled analysis and systematic review of EPA vs DHA alone, DHA was found to increase LDL-C compared with placebo while EPA was found to minimally affect LDL-C. ${ }^{63,66}$ In a preclinical animal study, DHA but not EPA, was found to significantly decrease hepatic LDL receptor expression and increase plasma cholesteryl ester transfer protein activity; recent data suggest that the LDL 
Table 4 Head-to-head comparison of the lipid effects of omega-3-acid ethyl esters vs omega-3-acid ethyl esters A in a I2-week doubleblind study in patients with severe hypertriglyceridemia

\begin{tabular}{llllll}
\hline $\begin{array}{l}\text { Median percent } \\
\text { change in lipid } \\
\text { parameters }\end{array}$ & $\begin{array}{l}\text { Omega-3-acid } \\
\text { ethyl esters A } \\
(\mathbf{n}=104)\end{array}$ & $\begin{array}{l}\text { Omega-3-acid } \\
\text { ethyl esters } \\
(\mathbf{n}=1 \mathbf{0 3})\end{array}$ & $\begin{array}{l}\text { Placebo } \\
\mathbf{( n = 4 3 )}\end{array}$ & $\begin{array}{l}\text { Median difference: } \\
\text { omega-3-acid ethyl } \\
\text { esters A vs placebo }\end{array}$ & $\begin{array}{l}\text { P-value } \\
\text { (omega-3-acid ethyl } \\
\text { esters A vs placebo) }\end{array}$ \\
\hline TG & $-24.7 \%$ & $-26.8 \%$ & $-17.4 \%$ & -12.2 & 0.0412 \\
LDL-C & $+20.3 \%$ & $+12.8 \%$ & $-5.9 \%$ & +24.7 & 0.0002 \\
Non-HDL-C & $-9.2 \%$ & $-3.6 \%$ & $-0.8 \%$ & -8.5 & 0.0258 \\
VLDL-C & $-21.2 \%$ & $-18.1 \%$ & $+5.6 \%$ & -28.7 & 0.0008 \\
Apo B & $+3.8 \%$ & $+5.3 \%$ & $0 \%$ & +3.2 & 0.2088 \\
HDL-C & $0 \%$ & $0 \%$ & $0 \%$ & +3.6 & 0.3502 \\
TC & $-8.1 \%$ & $-1.0 \%$ & $-0.8 \%$ & -6.9 & 0.0331 \\
\hline
\end{tabular}

Note: Data from US Food and Drug Administration. Omtryg Medical Reviews. Food and Drug Administration; 20I4. Center for Drug Evaluation and Research. Available from: http://www.accessdata.fda.gov/drugsatfda_docs/nda/20I4/204977Origl s000MedR.pdf. Accessed March 2, 2016. ${ }^{65}$

Abbreviations: Apo B, apolipoprotein B; HDL-C, high-density lipoprotein cholesterol; LDL-C, low-density lipoprotein cholesterol; non-HDL-C, non-high-density lipoprotein cholesterol; TC, total cholesterol; TG, triglyceride; VLDL-C, very-low-density lipoprotein cholesterol.

receptor gene may be downregulated by DHA. ${ }^{67,68}$ DHA may also affect LDL-C levels via increased conversion of verylow-density lipoprotein to LDL and increased LDL particle size. ${ }^{63}$ Additionally, based on hamster data, the clearance of these LDL particles may be reduced as a result of decreased hepatic expression of LDL by DHA. ${ }^{67}$

Reductions in non-HDL-C levels have been reported for all prescription OM3FAs compared with placebo (Table 3). ${ }^{12,21,23,24}$ In addition, significant reductions in Apo $\mathrm{B}$ and high-sensitivity C-reactive protein (hsCRP) have been reported with icosapent ethyl compared with placebo (Table 3). ${ }^{12,69}$ However, in clinical studies of patients with very high TG levels who were given DHA-containing OM3FA prescription products, Apo B levels were found to increase (Tables 3 and 4). ${ }^{23,65}$

\section{Plasma OM3FA levels}

Although direct comparisons of plasma OM3FA levels achieved in patients with elevated TG levels are not available, data from the individual clinical studies of icosapent ethyl and omega-3-carboxylic acids suggest that the end-oftreatment plasma EPA concentration achieved with icosapent ethyl $4 \mathrm{~g}$ /day is comparable to the total concentration of OM3FA (EPA+DHA) achieved with omega-3-carboxylic acids $4 \mathrm{~g}$ /day. ${ }^{15,70}$

\section{Prescription OM3FA considerations for endocrinologists/diabetologists Clinical data in diabetes and/or metabolic syndrome}

Studies of prescription OM3FAs in subgroups of patients with diabetes and/or metabolic syndrome have been published for the prescription EPA-only product (icosapent ethyl) and demonstrate beneficial effects on atherogenic parameters. In the sub-analysis of patients with T2DM from the ANCHOR study involving more than 500 patients, icosapent ethyl $4 \mathrm{~g}$ /day significantly reduced TG levels $(-23.2 \% ; P<0.0001)$ without raising LDL-C levels $(-6.3 ; P=0.02)$ at 12 weeks compared with placebo. ${ }^{28}$ Significant reductions were also observed in levels of non-HDL-C (-14.4\%; $P<0.0001)$ and Apo B $(-9.5 \%$; $P<0.0001)$ as well as hsCRP $(-21.5 \% ; P<0.01)$ compared with placebo. ${ }^{28} \mathrm{~A}$ subgroup analysis examining patients with metabolic syndrome $(n=849)$ who had participated in the ANCHOR and MARINE studies (the latter investigating the efficacy and safety of icosapent ethyl in reducing TG levels and other lipid parameters in patients with very high TG levels $[\geq 500 \mathrm{mg} / \mathrm{dL}]$ ) reported similar findings. ${ }^{71}$ At 12 weeks, patients treated with icosapent ethyl $4 \mathrm{~g} /$ day who had metabolic syndrome in the ANCHOR study ( $\mathrm{n}=211$; all patients on stable statin therapy) had significant reductions in levels of TG (median percentage change from baseline of $-21.7 \%$; $P<0.0001)$, non-HDL-C (-13.5; $P<0.0001)$, Apo B $(-8.8 \%$; $P<0.0001)$, and hsCRP $(-23.0 \% ; P<0.001)$ compared with placebo, without increasing LDL-C levels $(-5.2 \% ; P<0.05) .{ }^{71}$ Among patients treated with icosapent ethyl $4 \mathrm{~g} /$ day who had metabolic syndrome in the MARINE study ( $n=65)$, at 12 weeks, significant reductions were demonstrated in levels of TG $(-35.0 \% ; P<0.0001)$, non-HDL-C $(-19.9 \% ; P<0.0001)$, Apo B $(-9.1 \% ; P<0.01)$, and hsCRP $(-40.0 \% ; P<0.001)$ compared with placebo, again without increasing LDL-C levels $(-3.2 \% ; P>0.05)$; significant improvements were observed in patients both with and without concomitant statin therapy.

A "real-world" perspective on the use of prescription OM3FAs can be gained from a recent retrospective case series $(n=10)$ of patients with diabetes or prediabetes in our private endocrinology practice. ${ }^{72}$ The impact of switching from a prescription OM3FA containing a combination of 
DHA and EPA (omega-3-acid ethyl esters) to the EPA-only prescription product (icosapent ethyl) was assessed. Patients had been switched because of compliance issues caused by gastrointestinal side effects and fishy eructation experienced with the EPA+DHA formulation; the EPA-only formulation offered the potential for fewer gastrointestinal effects with no adverse effects on LDL-C levels. The EPA-only formulation was well tolerated, and the majority $(8 / 10)$ of patients experienced decreased or stable TG levels and decreased non-HDL-C, LDL-C, and total cholesterol levels.

\section{Impact on cardiovascular outcomes}

Prescription OM3FAs may be an important add-on therapy to statins for the reduction of residual CVD risk. Although the results of trials assessing the impact of OM3FAs for CVD risk reduction have been inconsistent, such studies completed to date have evaluated relatively low doses (typically 1-2 g/day) and did not necessarily target patients needing TG reduction; thus, they may not provide an accurate gauge of the potential benefits of prescription OM3FAs (at approved doses) in appropriate patient populations. ${ }^{73,74}$ However, the JELIS study demonstrated that high-purity prescription EPA $1.8 \mathrm{~g} /$ day as add-on to statin therapy reduced the relative risk of major coronary events (primary endpoint) by $19 \%$ compared with statin therapy alone $(P=0.011)$ in a Japanese population with hypercholesterolemia; the $1.8 \mathrm{~g} /$ day dosage of EPA was considered to be therapeutic in this population with high baseline fish intake. ${ }^{75}$ In a subgroup analysis of the JELIS study, patients with abnormal TG and HDL-C levels (TG $\geq 150 \mathrm{mg} / \mathrm{dL}$; HDL-C $<40 \mathrm{mg} / \mathrm{dL}$ ) had a significantly higher risk for major coronary events (hazard ratio [HR]: $1.71 ; 95 \%$ confidence interval $[\mathrm{CI}]: 1.11-2.64 ; P=0.014)$ compared with patients with normal TG and HDL-C levels; in this higher-risk group, EPA treatment reduced the risk of major coronary events by $53 \%$ (HR: 0.47 ; $95 \%$ CI: $0.23-0.98$; $P=0.043) .^{76}$

Cardiovascular outcomes data for OM3FAs in patients with diabetes or at risk for diabetes are limited. Of interest, a subgroup analysis of JELIS focusing on patients with impaired glucose metabolism (IGM) found that patients with IGM had increased cardiovascular risk compared with normoglycemic patients, and that EPA treatment reduced cardiovascular risk in patients with IGM. ${ }^{77}$ In contrast, the ORIGIN trial found that EPA+DHA treatment did not reduce death from cardiovascular causes over 6 years in patients with dysglycemia (ie, T2DM, impaired glucose tolerance, or impaired fasting glucose) and additional cardiovascular risk factors. However, it may be worth noting that the OM3FA dose (of both EPA and DHA) assessed was only $1 \mathrm{~g}$ /day in the ORIGIN study. ${ }^{60}$ Presently, the ADA does not recommend OM3FA supplements to treat or prevent CVD in patients with diabetes. ${ }^{18}$ An ongoing cardiovascular outcomes study of patients with diabetes, ASCEND (NCT00135226), will assess whether an EPA+DHA formulation plus aspirin $100 \mathrm{mg}$ can prevent serious vascular events in patients with diabetes; however, the dose of OM3FA is again only $1 \mathrm{~g} /$ day. ${ }^{78}$

Two additional ongoing studies are evaluating the effects of prescription-strength doses of OM3FAs on cardiovascular outcomes in patients at high risk for CVD. ${ }^{79,80}$ While these trials are not focused on patients with diabetes per se, they will include patients with T2DM and the results will help establish whether prescription OM3FAs are able to reduce residual cardiovascular risk. The STRENGTH study (NCT02104817) will evaluate the impact of omega-3-carboxylic acids plus a statin on cardiovascular outcomes. ${ }^{79}$ The REDUCE-IT study (NCT01492361) will evaluate the impact of adding the EPAonly formulation (icosapent ethyl, $4 \mathrm{~g}$ /day) to statin therapy on cardiovascular outcomes. ${ }^{80}$

\section{Additional considerations}

There is an urgent need for reduction of residual CVD risk in patients with T2DM and/or metabolic syndrome. Prescription OM3FAs are an effective treatment strategy that may help meet this "call to action". Several clinical practice guidelines recognize the role of prescription OM3FAs in patients who require TG reduction despite controlled LDL-C with statin therapy, and available data in patients with T2DM and/or metabolic syndrome are promising for the EPA-only product, icosapent ethyl. In addition, given their well-characterized safety profiles, prescription OM3FAs are a rational treatment consideration as add-on therapy to statins in patients with T2DM and/or metabolic syndrome who have elevated TG levels. It is important to avoid compromising LDL-C treatment goals, particularly in these patients. The EPA-only formulation offers an option that is effective but does not complicate management: while products containing both EPA and DHA may raise LDL-C, the EPA-only product, icosapent ethyl, does not. Cases from our clinical practice support that patients with diabetes or prediabetes can be safely and effectively switched from omega-3-acid ethyl esters to icosapent ethyl.

Findings from the IMPROVE-IT study, as well as exploratory analyses of proprotein convertase subtilisin/kexin type 9 outcome studies support the concept that incremental reductions in LDL-C levels can have a significant impact on reducing coronary artery disease events. ${ }^{81-83}$ These findings 
not only underscore the value of add-on therapy to statins, but also provide a rationale for avoiding treatments that could increase LDL-C levels. The effectiveness of prescription OM3FAs in reducing TG levels is well established, and ongoing outcomes studies of prescription OM3FAs will help determine whether these products will emerge as an effective add-on option to statin therapy for reduction of residual cardiovascular risk.

\section{Acknowledgments}

Medical writing assistance was provided by Peloton Advantage, LLC, Parsippany, NJ, USA, and funded by Amarin Pharma, Inc., Bedminster, NJ, USA. Medical scientific reference checks and associated assistance was provided by Joy Bronson of Amarin Pharma Inc. and Sumita Chowdhury, MD, MPH, FACC, MBA, consultant to Amarin Pharma Inc.

\section{Disclosure}

Amir Hassan, MD, has received grant/research support from, and is a stock shareholder of Amarin Pharma Inc. Nadeem Tajuddin, MD, and Ali Shaikh, MD, have no potential conflicts of interest to disclose in this work.

\section{References}

1. Grundy SM. Metabolic syndrome pandemic. Arterioscler Thromb Vasc Biol. 2008;28(4):629-636.

2. Alberti KG, Eckel RH, Grundy SM, et al. Harmonizing the metabolic syndrome: a joint interim statement of the International Diabetes Federation Task Force on Epidemiology and Prevention; National Heart, Lung, and Blood Institute; American Heart Association; World Heart Federation; International Atherosclerosis Society; and International Association for the Study of Obesity. Circulation. 2009;120(16): 1640-1645.

3. Haffner SM, Lehto S, Ronnemaa T, Pyorala K, Laakso M. Mortality from coronary heart disease in subjects with type 2 diabetes and in nondiabetic subjects with and without prior myocardial infarction. $N$ Engl J Med. 1998;339(4):229-234.

4. Berglund L, Brunzell JD, Goldberg AC, et al. Evaluation and treatment of hypertriglyceridemia: an endocrine society clinical practice guideline. J Clin Endocrinol Metab. 2012;97(9):2969-2989.

5. Jorgensen AB, Frikke-Schmidt R, West AS, Grande P, Nordestgaard BG, Tybjaerg-Hansen A. Genetically elevated non-fasting triglycerides and calculated remnant cholesterol as causal risk factors for myocardial infarction. Eur Heart J. 2013;34(24):1826-1833.

6. Jacobson TA, Ito MK, Maki KC, et al. National Lipid Association recommendations for patient-centered management of dyslipidemia: part 1 - executive summary. J Clin Lipidol. 2014;8(5):473-488.

7. Querton L, Buysschaert M, Hermans MP. Hypertriglyceridemia and residual dyslipidemia in statin-treated, patients with diabetes at the highest risk for cardiovascular disease and achieving very-low low-density lipoprotein-cholesterol levels. J Clin Lipidol. 2012;6(5): 434-442.

8. Fruchart JC, Davignon J, Hermans MP, et al. Residual macrovascular risk in 2013: what have we learned? Cardiovasc Diabetol. 2014;13:26.

9. Harris WS, Ginsberg HN, Arunakul N, et al. Safety and efficacy of Omacor in severe hypertriglyceridemia. J Cardiovasc Risk. 1997; $4(5-6): 385-391$.
10. Pownall HJ, Brauchi D, Kilinc C, et al. Correlation of serum triglyceride and its reduction by omega-3 fatty acids with lipid transfer activity and the neutral lipid compositions of high-density and low-density lipoproteins. Atherosclerosis. 1999;143(2):285-297.

11. Davidson MH, Stein EA, Bays HE, et al. Efficacy and tolerability of adding prescription omega-3 fatty acids $4 \mathrm{~g} / \mathrm{d}$ to simvastatin $40 \mathrm{mg} / \mathrm{d}$ in hypertriglyceridemic patients: an 8-week, randomized, double-blind, placebo-controlled study. Clin Ther. 2007;29(7):1354-1367.

12. Bays HE, Ballantyne CM, Kastelein JJ, Isaacsohn JL, Braeckman RA, Soni PN. Eicosapentaenoic acid ethyl ester (AMR101) therapy in patients with very high triglyceride levels (from the Multi-center, plAcebo-controlled, Randomized, double-bliNd, 12-week study with an open-label Extension [MARINE] trial). Am J Cardiol. 2011;108(5):682-690.

13. Ballantyne CM, Bays HE, Kastelein JJ, et al. Efficacy and safety of eicosapentaenoic acid ethyl ester (AMR101) therapy in statin-treated patients with persistent high triglycerides (from the ANCHOR study). Am J Cardiol. 2012;110(7):984-992.

14. Kastelein JJP, Maki KC, Susekov A, et al. Omega-3 free fatty acids for the treatment of severe hypertriglyceridemia: the EpanoVa fOr Lowering Very high triglyceridEs (EVOLVE) trial. J Clin Lipidol. 2014;8(1):94-106.

15. Maki KC, Orloff DG, Nicholls SJ, et al. A highly bioavailable omega-3 free fatty acid formulation improves the cardiovascular risk profile in high-risk, statin-treated patients with residual hypertriglyceridemia (the ESPRIT trial). Clin Ther. 2013;35(9):1400-1411.

16. Garber AJ, Abrahamson MJ, Barzilay JI, et al. Consensus statement by the American Association of Clinical Endocrinologists and American College of Endocrinology on the comprehensive type 2 diabetes management algorithm - 2016 executive summary. Endocr Pract. 2016;22(1):84-113.

17. Handelsman Y, Bloomgarden ZT, Grunberger G, et al. American association of clinical endocrinologists and american college of endocrinology - clinical practice guidelines for developing a diabetes mellitus comprehensive care plan - 2015. Endocr Pract. 2015;21(Suppl 1): $1-87$.

18. American Diabetes Association. Standards of medical care in diabetes 2016. Diabetes Care. 2016;39(Suppl 1):S1-S112.

19. Clinical Guidelines Task Force. Global guideline for type 2 diabetes. Brussels, Belgium: International Diabetes Federation; 2012.

20. Lovaza [package insert]. Research Triangle Park, NC: GlaxoSmithKline; 2013.

21. Lovaza [package insert]. Research Triangle Park, NC: GlaxoSmithKline; 2014.

22. Vascepa [package insert]. Bedminster, NJ: Amarin Pharma Inc.; 2015.

23. Epanova [package insert]. Wilmington, DE: AstraZeneca Pharmaceuticals LP; 2014.

24. Omtryg [package insert]. Arlington, VA: Trygg Pharma, Inc.; 2014.

25. Hartweg J, Perera R, Montori V, Dinneen S, Neil HA, Farmer A. Omega-3 polyunsaturated fatty acids (PUFA) for type 2 diabetes mellitus. Cochrane Database Syst Rev. 2008;(1):CD003205.

26. Reis CE, Landim KC, Nunes AC, Dullius J. Safety in the hypertriglyceridemia treatment with $\mathrm{N}-3$ polyunsaturated fatty acids on glucose metabolism in subjects with type 2 diabetes mellitus. Nutr Hosp. 2014;31(2):570-576.

27. Akinkuolie AO, Ngwa JS, Meigs JB, Djousse L. Omega-3 polyunsaturated fatty acid and insulin sensitivity: a meta-analysis of randomized controlled trials. Clin Nutr. 2011;30(6):702-707.

28. Brinton EA, Ballantyne CM, Bays HE, Kastelein JJ, Braeckman RA, Soni PN. Effects of icosapent ethyl on lipid and inflammatory parameters in patients with diabetes mellitus-2, residual elevated triglycerides (200-500 mg/dL), and on statin therapy at LDL-C goal: the ANCHOR study. Cardiovasc Diabetol. 2013;12:100.

29. Amend KL, Landon J, Thyagarajan V, Niemcryk S, McAfee A. Incidence of hospitalized rhabdomyolysis with statin and fibrate use in an insured US population. Ann Pharmacother. 2011;45(10):1230-1239. 
30. Lopid [package insert]. New York, NY: Parke-Davis; 2010.

31. Niaspan [package insert]. North Chicago, IL: AbbVie Inc.; 2013.

32. Trilipix [package insert]. North Chicago, IL: AbbVie Inc.; 2015.

33. Niaspan [package insert]. North Chicago, IL: AbbVie Inc.; 2015.

34. Capuzzi DM, Guyton JR, Morgan JM, et al. Efficacy and safety of an extended-release niacin (Niaspan): a long-term study. Am J Cardiol. 1998;82(12A):74U-81U.

35. Davidson MH, Rosenson RS, Maki KC, et al. Effects of fenofibric acid on carotid intima-media thickness in patients with mixed dyslipidemia on atorvastatin therapy: randomized, placebo-controlled study (FIRST). Arterioscler Thromb Vasc Biol. 2014;34(6):1298-1306.

36. Goldberg AC, Bays HE, Ballantyne CM, et al. Efficacy and safety of ABT-335 (fenofibric acid) in combination with atorvastatin in patients with mixed dyslipidemia. Am J Cardiol. 2009;103(4):515-522.

37. Jones $\mathrm{PH}$, Davidson MH, Kashyap ML, et al. Efficacy and safety of ABT-335 (fenofibric acid) in combination with rosuvastatin in patients with mixed dyslipidemia: a phase 3 study. Atherosclerosis. 2009;204(1):208-215.

38. Mohiuddin SM, Pepine CJ, Kelly MT, et al. Efficacy and safety of ABT-335 (fenofibric acid) in combination with simvastatin in patients with mixed dyslipidemia: a phase 3, randomized, controlled study. $\mathrm{Am}$ Heart J. 2009;157(1):195-203.

39. Braeckman RA, Stirtan WG, Soni PN. Effects of icosapent ethyl (eicosapentaenoic acid ethyl ester) on pharmacokinetic parameters of rosiglitazone in healthy subjects. Clin Pharmacol Drug Dev. 2015; 4(2):143-148.

40. Braeckman RA, Stirtan WG, Soni PN. Effect of concomitant icosapent ethyl (eicosapentaenoic acid ethyl ester) on the pharmacokinetics of atorvastatin. Clin Drug Investig. 2015;35(1):45-51.

41. Braeckman RA, Stirtan WG, Soni PN. Phase 1 study of the effect of icosapent ethyl on warfarin pharmacokinetic and anticoagulation parameters. Clin Drug Investig. 2014;34(7):449-456.

42. Braeckman RA, Stirtan WG, Soni PN. Effect of icosapent ethyl (eicosapentaenoic acid ethyl ester) on omeprazole plasma pharmacokinetics in healthy adults. Drugs R D. 2014;14(3):159-164.

43. McKenney JM, Swearingen D, Di Spirito M, et al. Study of the pharmacokinetic interaction between simvastatin and prescription omega-3-acid ethyl esters. J Clin Pharmacol. 2006;46(7):785-791.

44. Gosai P, Liu J, Doyle RT, et al. Effect of omega-3-acid ethyl esters on the steady-state plasma pharmacokinetics of rosuvastatin in healthy adults. Expert Opin Pharmacother. 2008;9(17):2947-2953.

45. Di Spirito M, Morelli G, Doyle RT, Johnson J, McKenney J. Effect of omega-3-acid ethyl esters on steady-state plasma pharmacokinetics of atorvastatin in healthy adults. Expert Opin Pharmacother 2008;9(17):2939-2945.

46. Bays HE. Safety considerations with omega-3 fatty acid therapy. Am J Cardiol. 2007;99(6A):35C-43C.

47. Harris WS. Expert opinion: omega- 3 fatty acids and bleeding-cause for concern? Am J Cardiol. 2007;99(6A):44C-46C.

48. Wachira JK, Larson MK, Harris WS. n-3 Fatty acids affect haemostasis but do not increase the risk of bleeding: clinical observations and mechanistic insights. Br J Nutr. 2014;111(9):1652-1662.

49. Bradberry JC, Hilleman DE. Overview of omega-3 fatty acid therapies. P T. 2013;38(11):681-691.

50. Collins N, Tighe AP, Brunton SA, Kris-Etherton PM. Differences between dietary supplement and prescription drug omega-3 fatty acid formulations: a legislative and regulatory perspective. J Am Coll Nutr. 2008;27(6):659-666.

51. Lopez JA, Ito MK. PLA chapter update: prescription fish oil and Blue Cross of Idaho. LipidSpin. 2010;8(3):32-34.

52. Kleiner AC, Cladis DP, Santerre CR. A comparison of actual versus stated label amounts of EPA and DHA in commercial omega-3 dietary supplements in the United States. J Sci Food Agric. 2015;95(6): 1260-1267.

53. Albert BB, Derraik JG, Cameron-Smith D, et al. Fish oil supplements in New Zealand are highly oxidised and do not meet label content of n-3 PUFA. Sci Rep. 2015;5:7928.
54. Ritter JC, Budge SM, Jovica F. Quality analysis of commercial fish oil preparations. J Sci Food Agric. 2013;93(8):1935-1939.

55. Shim SM, Santerre CR, Burgess JR, Deardorff DC. Omega-3 fatty acids and total polychlorinated biphenyls in 26 dietary supplements. J Food Sci. 2003;68(8):2436-2440.

56. American Cancer Society. Dietary supplements: what is safe? American Cancer Society; 2015. Available from: http://www.cancer.org/acs/groups/ cid/documents/webcontent/002385-pdf.pdf. Accessed March 2, 2016.

57. health.gov [homepage on the Internet]. Regulatory information: Dietary supplement health and education act of 1994. Food and Drug Administration. Available from: http://health.gov/dietsupp/ch1.htm. Accessed March 2, 2016.

58. Cohen PA. Hazards of hindsight - monitoring the safety of nutritional supplements. N Engl J Med. 2014;370(14):1277-1280.

59. Zargar A, Ito MK. Long chain omega-3 dietary supplements: a review of the National Library of Medicine Herbal Supplement Database. Metab Syndr Relat Disord. 2011;9(4):255-271.

60. ORIGIN Trial Investigators, Bosch J, Gerstein HC, et al. n-3 fatty acids and cardiovascular outcomes in patients with dysglycemia. $N$ Engl $J$ Med. 2012;367(4):309-318.

61. American Diabetes Association. Standards of medical care in diabetes 2015. Diabetes Care. 2015;38(Suppl 1):S1-S93.

62. Expert Dyslipidemia Panel of the International Atherosclerosis Society Panel members. An International Atherosclerosis Society Position Paper: global recommendations for the management of dyslipidemia full report. J Clin Lipidol. 2014;8(1):29-60.

63. Jacobson TA, Glickstein SB, Rowe JD, Soni PN. Effects of eicosapentaenoic acid and docosahexaenoic acid on low-density lipoprotein cholesterol and other lipids: a review. J Clin Lipidol. 2012;6(1):5-18.

64. Nieman K, Dicklin M, Bell M, Rains T, Maki K. Relationship between baseline triglyceride concentration and triglyceride reduction with $4 \mathrm{~g} / \mathrm{d}$ long-chain omega-3 acid ethyl esters (1035.6). FASEB J. 2014; 28(1 Suppl):1035.6.

65. US Food and Drug Administration. Omtryg Medical Reviews. Food and Drug Administration; 2014. Center for Drug Evaluation and Research. Available from: http://www.accessdata.fda.gov/drugsatfda_docs/ nda/2014/204977Orig1s000MedR.pdf. Accessed March 2, 2016.

66. Wei MY, Jacobson TA. Effects of eicosapentaenoic acid versus docosahexaenoic acid on serum lipids: a systematic review and meta-analysis. Curr Atheroscler Rep. 2011;13(6):474-483.

67. Ishida $T$, Ohta M, Nakakuki M, et al. Distinct regulation of plasma LDL cholesterol by eicosapentaenoic acid and docosahexaenoic acid in high fat diet-fed hamsters: participation of cholesterol ester transfer protein and LDL receptor. Prostaglandins Leukot Essent Fatty Acids. 2013;88(4):281-288.

68. Dawson K, Zhao L, Adkins Y, et al. Modulation of blood cell gene expression by DHA supplementation in hypertriglyceridemic men. J Nutr Biochem. 2012;23(6):616-621.

69. Bays HE, Ballantyne CM, Braeckman RA, Stirtan WG, Soni PN. Icosapent ethyl, a pure ethyl ester of eicosapentaenoic acid: effects on circulating markers of inflammation from the MARINE and ANCHOR studies. Am J Cardiovasc Drugs. 2013;13(1):37-46.

70. Braeckman RA, Bays HE, Ballantyne CM, Stirtan WG, Soni PN. Pharmacokinetic and triglyceride-lowering pharmacodynamic effects of icosapent ethyl (eicosapentaenoic acid ethyl ester) across clinical studies. Poster presented at: Annual Scientific Sessions of the American Heart Association; November 16-20; 2013; Dallas, TX.

71. Bays HE, Ballantyne CM, Braeckman RA, et al. Icosapent ethyl (eicosapentaenoic acid ethyl ester): effects upon high-sensitivity C-reactive protein and lipid parameters in patients with metabolic syndrome. Metab Syndr Relat Disord. 2015;13(6):239-247.

72. Hassan A, Tajuddin N, Shaikh A. Retrospective case series of patients with diabetes or prediabetes who were switched from omega-3-acid ethyl esters to icosapent ethyl. Cardiol Ther. 2015;4(1):83-93.

73. Risk and Prevention Study Collaborative Group. n-3 fatty acids in patients with multiple cardiovascular risk factors. $N$ Engl $\mathrm{J} \mathrm{Med}$. 2013;368(19):1800-1808. 
74. Yokoyama M, Origasa H; JELIS Investigators. Effects of eicosapentaenoic acid on cardiovascular events in Japanese patients with hypercholesterolemia: rationale, design, and baseline characteristics of the Japan EPA Lipid Intervention Study (JELIS). Am Heart J. 2003;146(4):613-620.

75. Yokoyama M, Origasa H, Matsuzaki M, et al. Effects of eicosapentaenoic acid on major coronary events in hypercholesterolaemic patients (JELIS): a randomised open-label, blinded endpoint analysis. Lancet. 2007;369(9567):1090-1098.

76. Saito Y, Yokoyama M, Origasa H, et al. Effects of EPA on coronary artery disease in hypercholesterolemic patients with multiple risk factors: sub-analysis of primary prevention cases from the Japan EPA Lipid Intervention Study (JELIS). Atherosclerosis. 2008;200(1):135-140.

77. Oikawa S, Yokoyama M, Origasa H, et al. Suppressive effect of EPA on the incidence of coronary events in hypercholesterolemia with impaired glucose metabolism: sub-analysis of the Japan EPA Lipid Intervention Study (JELIS). Atherosclerosis. 2009;206(2):535-539.

78. University of Oxford. ASCEND: a study of cardiovascular events in diabetes. Available from: http://clinicaltrials.gov/ct2/show/NCT001352 26?term=00135226\&rank=1. NLM identifier: NCT00135226. Accessed March 2, 2016.
79. AstraZeneca. Outcomes Study to Assess STatin Residual Risk Reduction With EpaNova in HiGh CV Risk PatienTs With Hypertriglyceridemia (STRENGTH). Available from: http://clinicaltrials.gov/ct2/show/ NCT02104817?term=strength+and+omega-3\&rank=3. NLM identifier: NCT02104817. Accessed March 2, 2016.

80. Amarin Pharma Inc. A study of AMR101 to evaluate its ability to reduce cardiovascular events in high risk patients with hypertriglyceridemia and on statin (REDUCE-IT). Available from: http://clinicaltrials.gov/show/ NCT01492361. NLM identifier: NCT01492361. Accessed March 2, 2016.

81. Cannon CP, Blazing MA, Giugliano RP, et al. Ezetimibe added to statin therapy after acute coronary syndromes. $N$ Engl J Med. 2015;372(25):2387-2397.

82. Sabatine MS, Giugliano RP, Wiviott SD, et al. Efficacy and safety of evolocumab in reducing lipids and cardiovascular events. $N$ Engl J Med. 2015;372(16):1500-1509.

83. Robinson JG, Farnier M, Krempf M, et al. Efficacy and safety of alirocumab in reducing lipids and cardiovascular events. $N$ Engl J Med. 2015;372(16):1489-1499.

\section{Publish your work in this journal}

Diabetes, Metabolic Syndrome and Obesity: Targets and Therapy is an international, peer-reviewed open-access journal committed to the rapid publication of the latest laboratory and clinical findings in the fields of diabetes, metabolic syndrome and obesity research. Original research, review, case reports, hypothesis formation, expert opinion and commentaries are all considered for publication. The manuscript management system is completely online and includes a very quick and fair peer-review system, which is all easy to use. Visit http://www.dovepress.com/testimonials.php to read real quotes from published authors.

Submit your manuscript here: http://www.dovepress.com/diabetes-metabolic-syndrome-and-obesity-targets-and-therapy-journal 